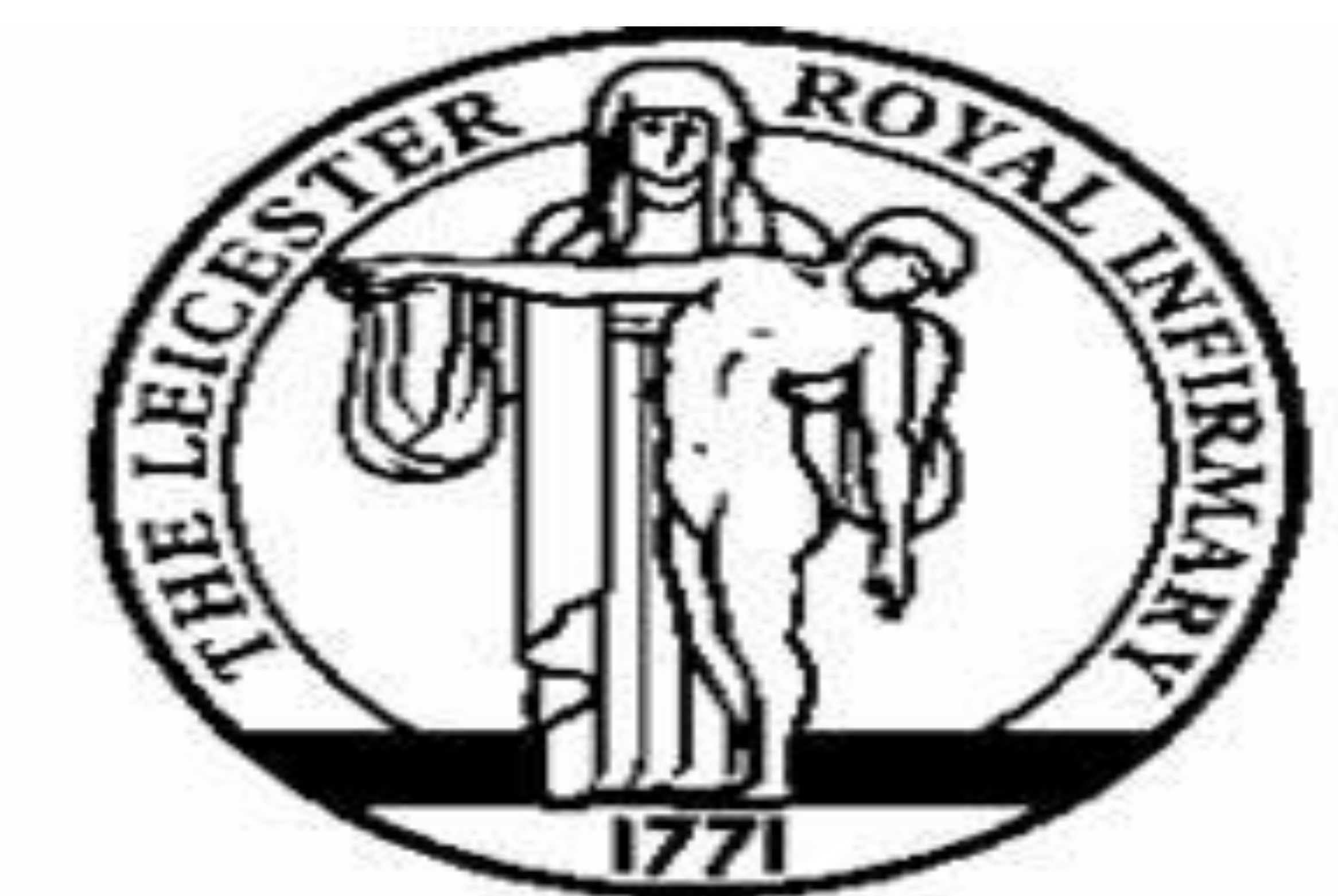

\title{
Papillary thyroid cancer within an auto-immune goitre: two birds with one stone
}

Bremner E, Kieffer V, Uddin FJ, Levy MJ

\section{Introduction}

University Hospitals of Leicester

Thyroid nodules in the context of hyperthyroidism are typically benign. However, thyroid cancer may be more common and aggressive in patients with Graves' disease. This patient presented with hyperthyroidism and a thyroid nodule, and the eventual diagnosis was a papillary thyroid cancer within an auto-immune goitre.

\section{Clinical presentation}

A 32 year old lady presented with a history of weight loss, sweating, tremor and anxiety and biochemical hyperthyroidism; fT $_{4} 41 \mathrm{pmols} / \mathrm{l}$ (9.00-25.00pmols/l) TSH $<0.05 \mathrm{miu} / \mathrm{l}$ [0.30-5.00miu/l); strongly positive TPO antibodies $[1600 \mathrm{lU} / \mathrm{ml}$.]. She was toxic clinically, had subtle left sided proptosis and a palpable left sided thyroid nodule. She was started on Carbimazole $20 \mathrm{mg}$ and the initial differential diagnosis was between Grave's disease and a toxic thyroid nodule.

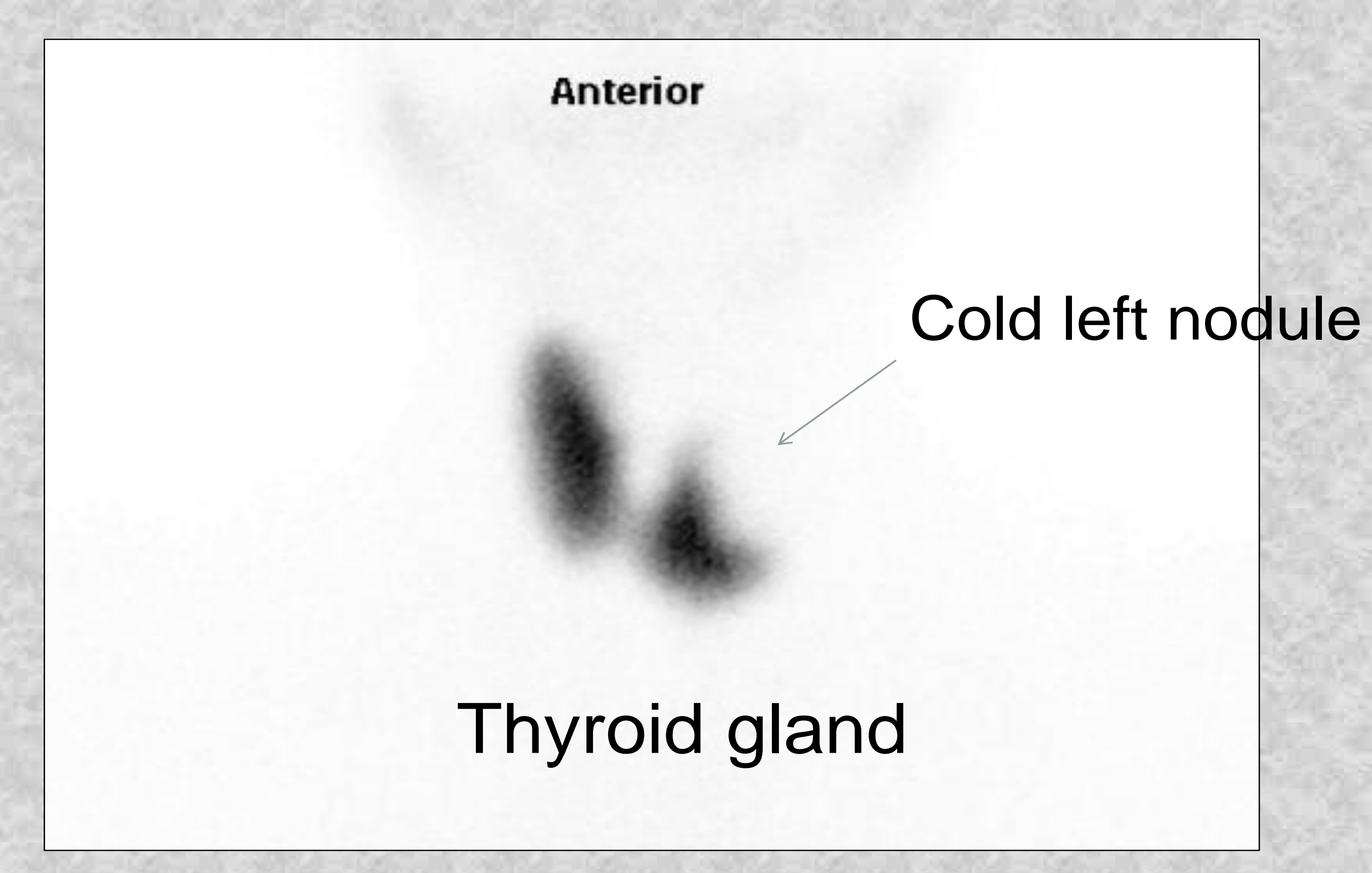

Figure 1. Tc uptake scan showing cold left nodule

\section{Further investigation}

A technetium uptake scan showed a cold nodule correlating clinically with the palpable nodule (Figure 1). Fine needle aspiration (FNA) demonstrated papillary thyroid cancer (Figure 2). On discussion with the patient, it was decided she would undergo a total thyroidectomy rather than hemi-thyroidectomy, to definitely treat her auto-immune hyperthyroidism as well as remove the malignant nodule.

\section{Surgery}

A total thyroidectomy was performed on $2^{\text {nd }}$ August 2016. Pathology showed a $25 \mathrm{~mm}$ classical papillary thyroid tumour which had advanced into the muscle. Following surgery persistent hypocalcaemia developed, requiring Alfacalcidol and Sandocal, alongside levothyroxine on discharge. Follow up plans include Radioactive lodine treatment, and monitoring of thyroid and calcium status.

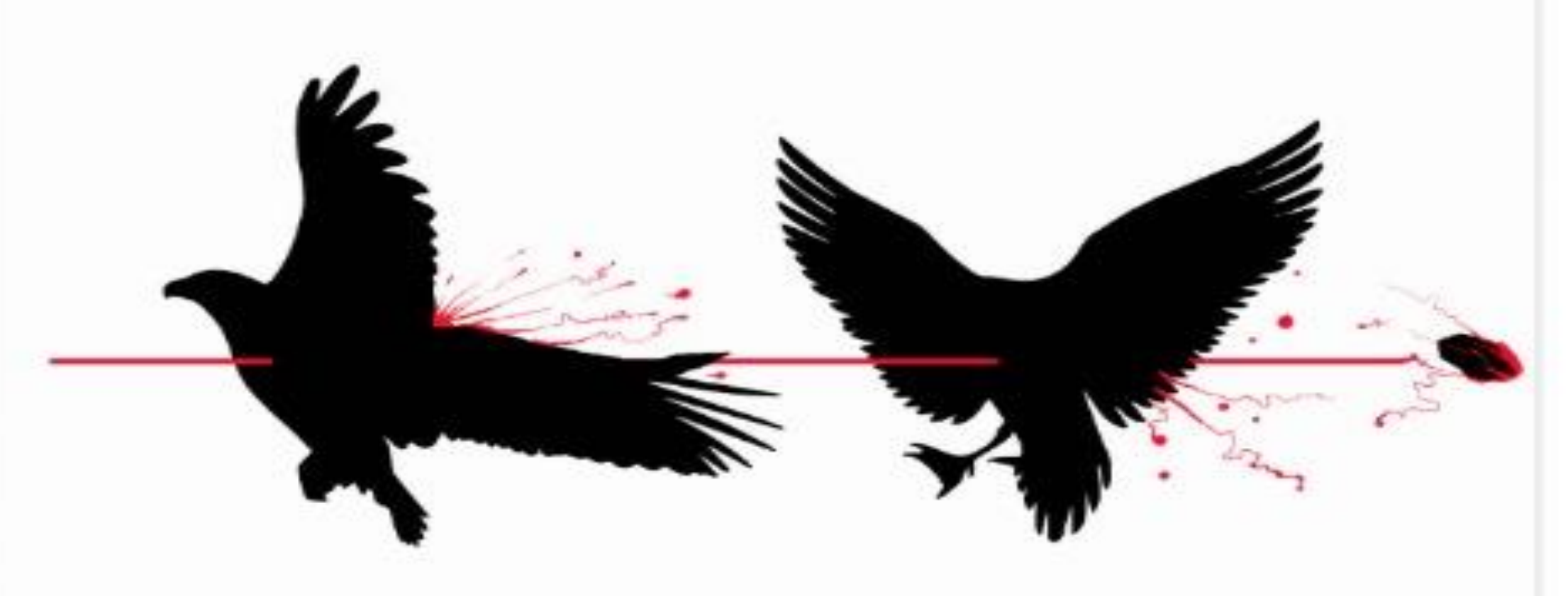

\section{Learning points}

This case demonstrates the importance of investigating thyroid nodules in the context of autoimmune hyperthyroidism, in case dual pathology exists. We recommended total thyroidectomy to remove the malignant lesion and definitively cure her hyperthyroidism, thereby killing two birds with one stone

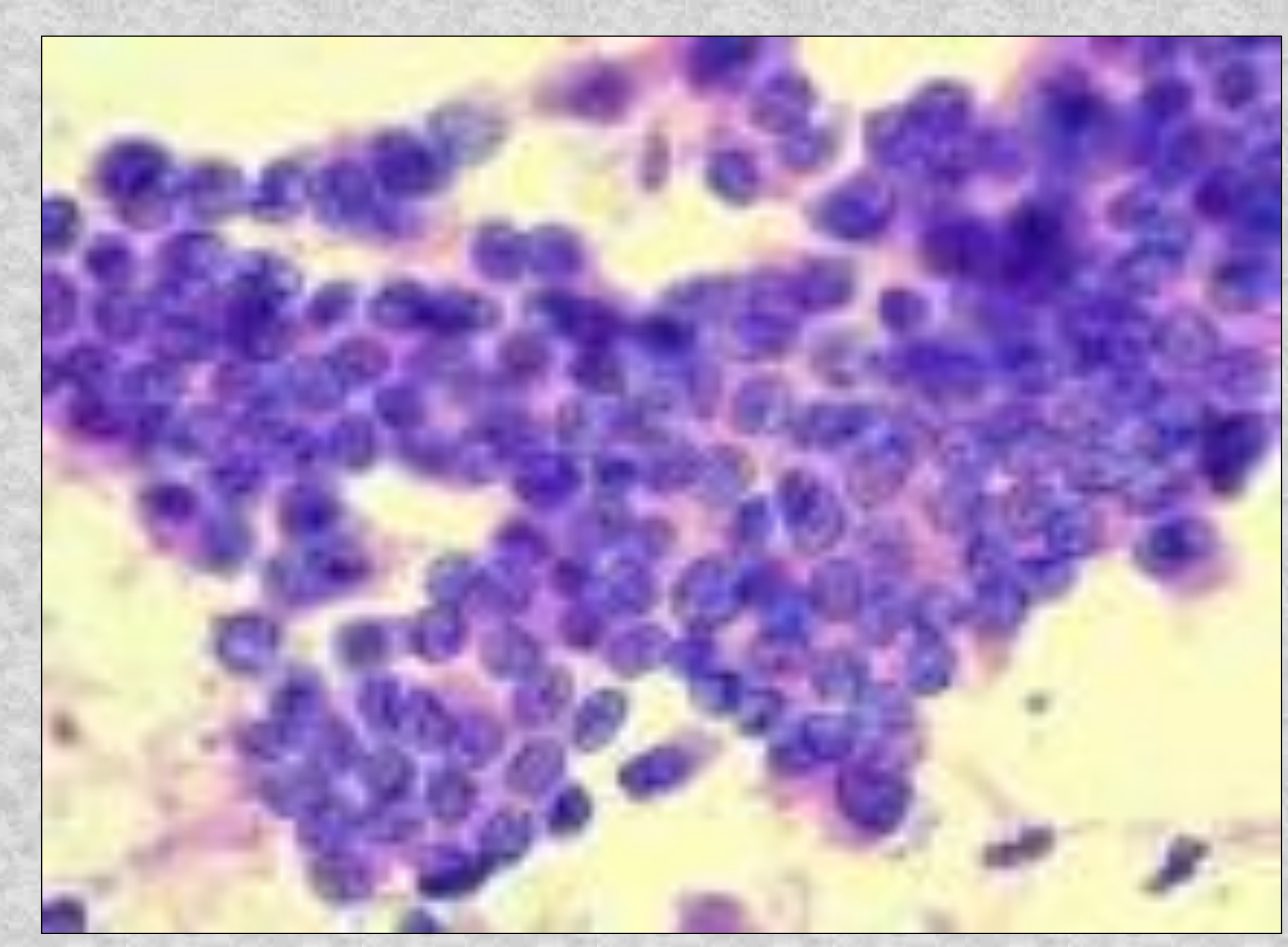

Figure 2. FNA cytology showing papillary cancer cells

References

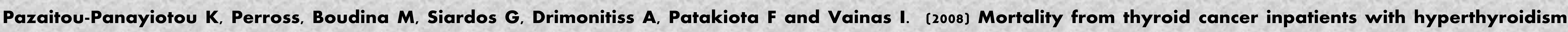
European Journal of Endocrinology. 159:799-803 